\title{
Identification of (8S,9S,10S)-8,10-dimethyl-1-octalin, a key intermediate in the biosynthesis of geosmin in bacteria
}

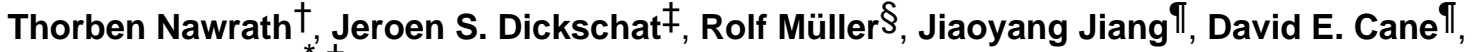 \\ and Stefan Schulz ${ }^{\star}, \dagger$ \\ Institut für Organische Chemie, Technische Universität Braunschweig, Hagenring 30, 38106 \\ Braunschweig, Germany, Department of Biochemistry, University of Cambridge, Cambridge CB2 \\ 1GA, UK, Institut für Pharmazeutische Biotechnologie, Universität des Saarlandes, 66041 \\ Saarbrücken, Germany, and Department of Chemistry, Brown University, Providence, Rhode \\ Island 02912-9108, USA
}

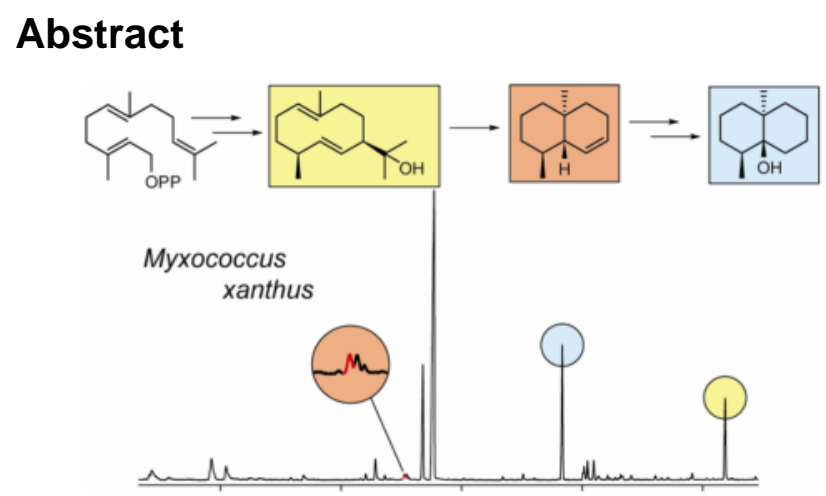

$(-)$-Geosmin $(\mathbf{1}$, blue $)$ is an important odor component produced by many bacteria, including actinomycetes, myxobacteria, and cyanobacteria, but has also been reported for eukaryotic organisms such as fungi, liverworts, insects, and plants. Recent research has shown that the biosynthesis of $\mathbf{1}$ starts with the cyclization of farnesyl pyrophosphate to $(1(10) E, 5 E)$ germacradien-11-ol (2, yellow), the first key intermediate en route. In a retro-Prins-reaction acetone is lost, and the second key intermediate, $(8 S, 9 S, 10 S)-8,10$-dimethyl-1-octalin (3, red), is formed. After reprotonation, a 1,2-H-shift and attack of water, geosmin is finally released. Octalin 3 occurs in the bouquets of volatiles released by myxobacteria as well as in enzyme extracts of incubation experiments of the purified geosmin synthase from Streptomyces coelicolor. Here the identification of $\mathbf{3}$, a new natural compound, the elucidation of its stereochemistry, and its synthesis are reported.

(-)-Geosmin (1) has a strong earthy smell and is an important odor component produced by many bacteria, including actinomycetes, myxobacteria, and cyanobacteria, as well as a number of eukaryotic organisms such as fungi, liverworts, insects, and plants. ${ }^{1,2}$ Geosmin was first described by Gerber and Lechevalier, who isolated it from the actinomycete

stefan.schulz@tu-bs.de.

†Technische Universität Braunschweig.

†University of Cambridge.

§Universität des Saarlandes.

IIIrown University.

Supporting Information Available: General methods and experimental information, as well as GC-MS data are available free of charge via the Internet at http://pubs.acs.org. 
Streptomyces griseus. ${ }^{2}$ Humans can detect extremely low levels (parts per trillion) of geosmin, which is also a frequently occurring off-flavor in water treatment and in fishery. 3,4 The biosynthesis of this degraded sesquiterpene $\mathbf{1}$ has recently received much attention and has been investigated in streptomycetes ${ }^{5,6}$ and myxobacteria. ${ }^{7}$ The pathway starts with the cyclization of farnesyl pyrophosphate (6) to (1(10)E,5E)-germacradien-11-ol (2). ${ }^{5 \mathrm{~d}, 7} \mathrm{~A}$ retro-Prins fragmentation results in the loss of acetone ${ }^{6}$ with the formation of 8,10dimethyl-1-octalin (6,10-dimethylbicyclo[4.4.0]dec-2-ene, $\mathbf{3})$ of unknown stereochemistry at the ring junction. After reprotonation of 3 and a 1,2-H-shift, ${ }^{5}$ final attack of water leads to $\mathbf{1}$ (Scheme 1). ${ }^{5 \mathrm{~d}, 6,7}$ Germacradienol $\mathbf{2}$ frequently occurs together with $\mathbf{1}$ in extracts or scent bouquets of myxobacteria and streptomycetes. ${ }^{8}$ Furthermore, $\mathbf{2}$ has been detected among the products of incubation of the purified geosmin synthase with FPP, and can also be converted to geosmin by the synthase, thus firmly establishing its role as an intermediate en route to $1 .^{5}$

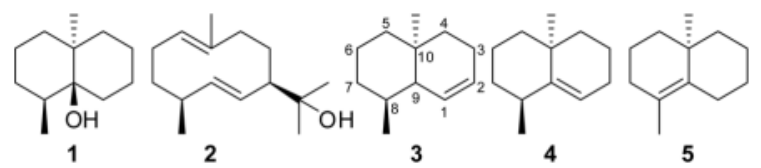

The bouquets of volatiles released by the myxobacteria Stigmatella aurantiaca and Myxococcus xanthus contain several unidentified $\mathrm{C}_{12} \mathrm{H}_{20}$ (m.w. 164) hydrocarbons whose mass spectra are similar to that of 8,10-dimethyl-1(9)-octalin $(6,10$ -

dimethylbicyclo[4.4.0]dec-1-ene, 4). ${ }^{9}$ Here we report on the identification of the latest key intermediate in the biosynthesis of $\mathbf{1}$, octalin $\mathbf{3}$, and a side product of geosmin biosynthesis, octalin 4.

During GC-MS analysis of the volatiles produced by the myxobacterium Myxococcus xanthus (Figure 1) we observed two compounds $\mathbf{A}$ and $\mathbf{B}$ with mass spectra (see supporting information) similar or identical to the published spectrum of $\mathbf{4},{ }^{9}$ showing the strong M-15 ion expected for dimethyloctalins. Control experiments ruled out formation of either $\mathbf{A}$ or $\mathbf{B}$ by decomposition of geosmin during GC-MS analysis.

Both of these octalin isomers are therefore likely intermediates or side products of geosmin biosynthesis. Besides 4 , previously found as a constituent in liverworts and mosses, ${ }^{10}$ the only previously described terpenoid dimethyloctalin is the synthetic compound 1,10dimethyl-1(9)-octalin (2,6-dimethylbicyclo[4.4.0]dec-1-ene, argosmin C, 5). ${ }^{11 \mathrm{~b}}$ Argosmin C has been obtained by treatment of $\mathbf{1}$ with conc. $\mathrm{HCl}$ together with four unknown $\mathrm{C}_{12} \mathrm{H}_{20}$ (m.w. 164) compounds, ${ }^{2,11}$ but unfortunately no mass spectrum has been published.

We have now synthesized the proposed intermediate 3 in order to confirm its structure and stereochemistry. $(R)$-2,6-dimethylcyclohexyl-1-phenylethylimine $(\mathbf{9})^{12}$ was transformed into 10 following a route described by Pfau et al. ${ }^{13}$ The enantiomerically enriched octalone 10 was treated with tosylhydrazine to yield the hydrazone 12, which upon exposure to $\mathrm{NaBH}_{4}{ }^{14}$ gave a 4:1 mixture of two diastereomers of $(1 S, 10 S)$-3, containing either a cis- or transfused octalin ring system. In accord with the mechanism of reduction of unsaturated hydrazones, ${ }^{15}$ the axial bridgehead methyl group at $\mathrm{C}-10$ in the hydrazone $\mathbf{1 2}$ directs the initial attack of the borohydride to the $\beta$-face of the ring. The resulting $\alpha$-diimide therefore transfers its $\mathrm{H}$-atom to the $\alpha$-face of $\mathrm{C}$-9. This retro-ene reaction expels the $\mathrm{N}$-substituent from the molecule, resulting in the cis-fused ring arrangement for the major reaction product, cis-3. The minor diastereomer is therefore trans-3. We chose this moderately stereoselective process to have an easy access to a defined mixture of both diastereomers of 3 , enriched each in one enantiomer, for comparison with the natural product. 
These stereochemical assignments are further corroborated by NMR experiments because of the known ${ }^{1} \mathrm{H}-\mathrm{NMR}$ shifts of bridgehead methyl groups in cis- and trans-octalin derivatives. ${ }^{16}$ For cis-compounds a value of $0.98 \mathrm{ppm}$ was reported, while the signal in the transisomers appeared around $0.85 \mathrm{ppm} .{ }^{16}$ The observed methyl chemical shifts of $0.81 \mathrm{ppm}$ for trans $\mathbf{- 3}$ and 0.98 ppm for cis $\mathbf{- 3}$ therefore support our configurational assignments. In addition, NOESY-experiments showed strong interactions between both methyl groups and the bridgehead hydrogen in case of $c i s-3$, while no such interaction was found between the C-10 methyl group and the bridgehead hydrogen in trans-3. Additional proof was obtained by synthesis of pure trans-3 by 1,4-reduction of octalone $\mathbf{1 0}$ with lithium, and trapping of the resulting enolate with diethyl chloro phosphate. This procedure is known to selectively furnish trans-fused octalins. ${ }^{17}$ The resulting enol phosphonate was then reduced with Li to furnish pure trans-3, albeit in low yield. ${ }^{17}$ Comparison with the naturally occurring compounds proved that compound $\mathbf{A}$ is identical to trans-3. The ring junction in trans-3 is therefore identical to the trans ring fusion of geosmin (1). Gas chromatographic analysis on a chiral phase showed that only the synthetic enantiomer $(8 S, 9 S, 10 S)$-8,10-dimethyl-1octalin (trans-3) occurs naturally.

Compound 4 was synthesized by transformation of octalone $\mathbf{1 0}$ into the dithioketal $\mathbf{1 3}$, followed by desulfurization with tributyltin hydride. ${ }^{18}$ Comparison of mass spectra, retention index, and co-injection confirmed the identity of $\mathbf{B}$ and $\mathbf{4}$. The formation of $\mathbf{4}$ during geosmin biosynthesis can be rationalized by loss of a proton from either cation $\mathbf{7}$ or $\mathbf{8}$ (Scheme 1). Both compounds 3 and $\mathbf{4}$ were also identified in several other myxobacteria such as Nannocystis exedens or in Streptomyces strains.

Both compounds $\mathbf{3}$ and $\mathbf{4}$ were also observed among the products resulting from incubation of farnesyl diphosphate (6) with the purified geosmin synthase from Streptomyces coelicolor, ${ }^{3 \mathrm{~d}}$ along with $\mathbf{1}, \mathbf{2}$, and germacrene $\mathrm{D}$ as main products. This experiment unambiguously proves that both $\mathbf{3}$ and $\mathbf{4}$ are formed by the geosmin synthase in streptomycetes, with 3 likely an intermediate and $\mathbf{4}$ being a shunt metabolite. The coocurrence of $\mathbf{3}$ and $\mathbf{4}$ in head-space extracts of geosmin-producing myxobacteria supports the same conclusion for these species. Incubation of deuterated octalin $\mathbf{3}$ with $S$. coelicolor geosmin synthase did not give rise to labeled geosmin, most likely because enzymatically generated $\mathbf{3}$ is normally processed by a transiently activated form of the geosmin synthase in which the distribution of charged residues resulting from the retro-Prins fragmentation of germacradienol $\mathbf{2}$ is distinct from the resting state of the enzyme. Similar lack of conversion of exogenously added sesquiterpenes by other terpene synthases has previously been observed. ${ }^{19}$ Nevertheless, the occurrence of $(8 S, 9 S, 10 S)-3$ both under natural conditions and in enzyme preparations suggests its key role in the biosynthesis of $\mathbf{1}$.

\section{Supplementary Material}

Refer to Web version on PubMed Central for supplementary material.

\section{Acknowledgments}

This work was supported by grants from the Deutsche Forschungsgemeinschat and the Fonds der Chemischen Industrie to S.S. and the N. I. H. (GM30301) to D.E.C.

\section{References and Notes}

1. a) Schulz S, Dickschat JS. Nat Prod Rep 2007;24:814-842. [PubMed: 17653361] b) Bjurman J, Kristensson J. Microbios 1992;72:47-54. c) Spiteller D, Jux A, Piel J, Boland W. Phytochemistry 2002;61:827-834. [PubMed: 12453575] d) La Guerche S, Chamont S, Blancard D, Dubourdieu D, Darriet P. Antonie van Leeuwenhoek 2005;88:131-139. [PubMed: 16096689] e) Spörle J, Becker 
H, Allen NS, Gupta MP. Z Naturforsch 1991;46c:183-188. f) Omura H, Kuwahara Y, Tanabe T. J Chem Ecol 2002;28:2601-2612. [PubMed: 12564803]

2. Gerber NN, Lechevalier HA. Appl Microbiol 1965;13:935-938. [PubMed: 5866039]

3. Jardine C, Gibson N, Hrudey S. Water Sci Technol 1999;40:91-98.

4. Schrader KK, Dennis ME. Water Res 2005;39:2807-2814. [PubMed: 15993924]

5. a) Cane DE, Watt RM. Proc Natl Acad Sci USA 2003;100:1547-1551. [PubMed: 12556563] b) He XF, Cane DE. J Am Chem Soc 2004;126:2678-2679. [PubMed: 14995166] c) Cane DE, He XF, Kobayashi S, Omura S, Ikeda H. J Antibiot 2006;59:471-479. [PubMed: 17080683] d) Jiang J, He X, Cane DE. J Am Chem Soc 2006;128:8128-8129. [PubMed: 16787064] e) Jiang J, He X, Cane DE. Nat Chem Biol 2007;310.1038/nchembio.2007.29

6. Jiang J, Cane DE. J Am Chem Soc. submitted (accompanying paper).

7. Dickschat JS, Bode HB, Mahmud T, Müller R, Schulz S. J Org Chem 2005;70:5174-5182. [PubMed: 15960521]

8. a) Pollack FC, Berger RG. Appl Env Microbiol 1996;62:1295-1299. [PubMed: 16535293] b) Dickschat JS, Wenzel SC, Bode HB, Müller R, Schulz S. Chem Bio Chem 2004;5:778-787. c) Dickschat JS, Brinkhoff T, Simon M, Schulz S. Chem Biodiver 2005;2:837-865. d) Dickschat JS, Bode HB, Wenzel SC, Müller R, Schulz S. Chem Bio Chem 2005;6:2023-2033. e) Dickschat JS, Reichenbach H, Wagner-Döbler I, Schulz S. Eur J Org Chem 2005:4141-4153. f) Dickschat JS, Nawrath T, Thiel V, Kunze B, Müller R, Schulz S. Angew Chem 2007;46:8287-8290. [PubMed: 17899580]

9. Joulain, D.; König, WA. The Atlas of Spectral Data of Sesquiterpene Hydrocarbons. E. B.-Verlag; Hamburg: 1998.

10. a) Rieck A, Bülow N, König WA. Phytochemistry 1995;40:847-851. b) Wu C-L, Lin S-C, Chen JA. J Chem Research 1991:50-51. c) Saritas Y, Sonwa MM, Iznaguen H, König WA, Muhle H, Mues R. Phytochemistry 2001;57:443-447. [PubMed: 11393526]

11. a) Gerber NN. Biotechnol Bioeng 1967;9:321-327. b) Gerber NN. Tetrahedron Lett 1968:29712974. c) Rosen AA, Safferman RS, Mashni CI, Romano AH. Appl Microbiol 1968;16:178-179. [PubMed: 5636464]

12. Carlson C, Larsson U, Hansson L. Acta Chem Scand 1992;46:1211-1214.

13. Pfau M, Revial G, Guingant A, d'Angelo J. J Am Chem Soc 1985;107:273-274.

14. Liu L, Xiong Z, Nan F, Li T, Li Y. Synth Commun 1995;25:1971-1975.

15. a) Shapiro RH. Org Reactions 1976;23:405-507. b) Taylor EJ, Djerassi C. J Am Chem Soc 1976;98:2275-2281.

16. Schmitz FJ, Peters CA. J Chem Soc C 1971;10:1905-1907.

17. Grieco PA, Nargund RP, Parker DT. J Am Chem Soc 1989;111:6287-6294.

18. Gutierrez CG, Stringham RA, Nitasaka T, Glasscock KG. J Org Chem 1980;45:3393-3395.

19. Cane, DE. Comprehensive Natural Products Chemistry. In: Cane, DE., editor. Isoprenoids Including Carotenoids and Steroids. Vol. 2. Elsevier; Oxford: 1999. p. 155-200. 


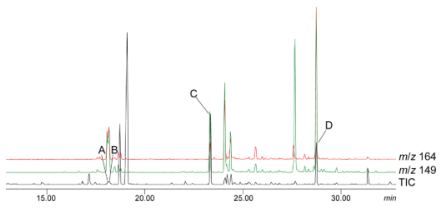

Figure 1.

Total ion chromatogram of a headspace extract of M. xanthus. A: $(8 S, 9 S, 10 S)-8,10-$

dimethyl-1-octalin (trans-3); B: (8S,10S)-8,10-dimethyl-1(9)-octalin (4); C: geosmin (1); D: (1(10)E,5E)-germacradien-11-ol (2). 


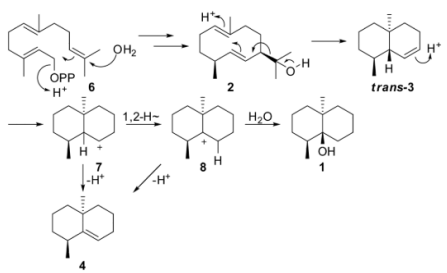

Scheme 1.

Biosynthesis of geosmin (1) in M. xanthus 


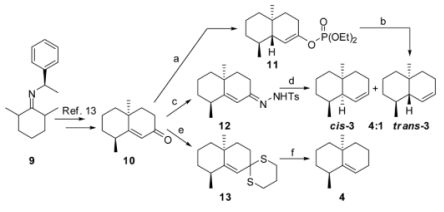

Scheme 2.

Synthesis of 8,10-dimethyl-1-octalin (3) and 8,10-dimethyl-1(9)-octalin (4). a) i. Li, $\mathrm{NH}_{3}$, ii. $\mathrm{ClPO}(\mathrm{OEt})_{2}(84 \%)$; b) Li, EtNH 2 (10\%); c) $\mathrm{TsNHNH}_{2}, \mathrm{BF}_{3} \cdot \mathrm{Et}_{2} \mathrm{O}(27 \%)$; d) i. conc. AcOH, ii. $\mathrm{NaBH}_{4}(52 \%$, ee $56 \%)$; e) $1,3-\mathrm{Pr}(\mathrm{SH})_{2}, \mathrm{BF}_{3} \cdot \mathrm{Et}_{2} \mathrm{O}(97 \%)$; f) $\mathrm{Bu}_{3} \mathrm{SnH}, \mathrm{AIBN}(50 \%)$ 